\title{
ASSESSMENT OF STAFF PERFORMANCE IN CSSD UNIT BY 360 DEGREE EVALUATION METHOD
}

\section{Leila Sadati', Afsaneh Askarkhah2, Sedigheh Hannani3, Mostfa Moazamfard4, Mahmood Abedinzade5, Parisa Mohammad Alinejad6, Nazanin Saraf3, Azin Arabkhazaei7, Azar Arabkhazaei7}

1. Faculty member. Department of Operating Room, School of Allied Medical Sciences. Alborz University of Medical Sciences. Karaj. Iran.

2. MSc of Operating Room, School of Allied Medical Sciences. Iran University of Medical Sciences. Tehran.Iran.

3. Faculty member. Department of Operating Room, School of Allied Medical Sciences. Iran University of Medical Sciences. Tehran Iran.

4. Faculty member. Department of Operating Room, School of Allied Medical Sciences. Behbahan University of Medical Sciences. Behbahan, Iran.

5. Department of physiology, Guilan University of Medical Sciences. Rasht, Iran.

6. MSc of nursing, School of nursing and midwifery, Guilan University of Medical Sciences. Rasht. Iran.

7. Faculty member. Department of Operating Room, School of Allied Medical Sciences. Gonabad University of Medical Sciences. Gonabad.Iran.

Correspondence: afsanehask7@gmail.com

\section{ABSTRACT}

\section{BACKGROUND:}

360-degree evaluation is a method that an employee is evaluated by the others and given feedback to him/her. Considering the proper implementation of the sterilization process is important in the prevention of nosocomial infections and has a direct impact on the quality of performance of the surgical team in the operating room. This study was conducted to the Evaluation of CSSD Unit Personnel Performance in Sterilization Process using the 360 Degree technique.

\section{METHODS:}

This cross-sectional study was conducted in the educational hospitals of Gillan Province in IRAN, between 2018 and 2019. Assessment of staff performance in CSSD Unit was done by 360 Degree evaluation method in five different stages. The evaluators included the infection control nurses, Supervisors of the sterilization unit, the researcher and the staff of these units as self-assessors.
Finally, the collected data were analyzed using SPSS version 20.

\section{RESULTS:}

The evaluation mean scores were as following: the researcher, $75.97 \pm 18.9$; infection control nurse, $87.62 \pm 7.2$; unit supervisor, $87.61 \pm 7.8$ and staff self-assessment, $88.01 \pm$ 8.1; at different stages of the sterilization process. From all assessors view, the highest and lowest scores were related to the cleaning and Health dimensions.

\section{CONCLUSION:}

According to assessor's agreement in scoring of different stages of the sterilization process, the 360-degree evaluation method is a valuable tool in assessment of the staff performance in important tasks. By applying this method, it can be ethically prevented evaluators' individual judgments.

\section{KEYWORDS}

Sterilization process, 360-degree evaluation, staff performance 


\section{INTRODUCTION}

According to the results of more studies in the operating room area, high levels of contamination on operating room equipment has been documented in numerous cases. For this reason, it is recommended that all health staff must be obeyed to standard guidelines for the prevention and control of nosocomial infections to reduce these infections effectively. [1] The heart of hospitals in infection control is the sterilization unit that Known as CSSD, CSR, SPD. This unit is responsible for providing sterile equipment and supply for operating rooms, inpatient and outpatients departments, transplant units, and other departments of hospital.[2] Sterilization refers to any process that removes and kills all forms of life, especially spores from surgical tools, and other critical equipment. [3] Tools, surgical instruments, fabrics, and gowns, and endoscopes are sterilized in this unit by sterilizer equipment like autoclave. [2] If medical supplies and instruments are not properly collected, disinfected and sterilized, they can spread the infection to patients and staff. it leads to the unfortunate consequences of surgery in the operating room. [4] Therefore, it is valuable to monitor the staff performance that they are responsible for the process of cleaning and decontamination, disinfection, packaging, sterilization, storage and transportation of instruments. There is no doubt that the staff qualification of the sterilization unit play an important role in completing the puzzle of the surgical team's performance quality. [5] The personnel of these units are responsible to guarantee non-transmission of infection through sterilized medical supplies and tools in their unit with proper procedures of sterilization and disinfection. Since it is not possible and costbeneficial for doing environmental microbial cultures in a continuous and repeated manner to ensure that a sterile product leaves the sterilization cycle. Therefore, it is recommended to monitor the sterilization process cycle with an accreditation program. [6-8] Accreditation is a strategy to improve the quality of hospital services. It consists of three components: accreditation standard, accreditation method, and accreditation evaluators. Therefore, failures of each component of the accreditation system can lead to failure to achieve the accreditation goals. [9] According to Mossadegh rad studies, the deficiencies of accreditation system are including the lack of procedural unity among the evaluators, the same weight of accreditation indexes, Lack of transparency of the measures, the high number of standards, and the low skill of the assessors. [10] The American Medical Education Accreditation Council has said the 360-degree technique is the best method to evaluate interpersonal and communication skills. In this method, by surveying all the employee at the workplace, the qualification of the staff performance evaluate by different evaluators. [11] Joshi (2004), Saraf (2019), and Hadinejad (2016) have identified the 360-degree tool as a high-reliability tool for assessment of the competencies and communication skills in their studies. [12-14] Baradaran et al. used a 360-degree tool to assess midwifery students' performance. They stated that 360-degree method is a valuable method in clinical performance assessment and it can be consider in educational planning. [11] The 360-degree evaluation has numerous benefits including gathering members together, increasing self-awareness, clarifying behaviors, identifying opportunities for promotion and accountability and responsibility. [15] However, its limitations, including cost, insufficient skills of evaluators, failure to properly perform due to poor leadership of the evaluator's team has led most of the studies related to evaluate the performance of the hospital staff was done by interview or direct observation only by one person at one time. Therefore, given the benefits of this assessment method and the critical role of staff performance in sterilization unit for preventing nosocomial infections, which has unfortunately been overlooked in many centers by managers, this study was conducted to Assessment of staff performance in CSSD Unit by 360 Degree evaluation method.

\section{MATERIAL AND METHOD}

This cross-sectional study was conducted in the educational hospitals of Gillan Province in IRAN, between 2018 and 2019. The study samples were 30 personnel working in the sterilization unit of these hospitals who were included in the census. The evaluators included the infection control nurses $(n=6)$, the supervisor of the sterilization unit $(n=6)$, the researcher $(n=1)$. and the staff of these units as self-assessors. The data collection tool was a researcher-made questionnaire. This questionnaire was made based on the questionnaire of the Infection Control Center of Infectious Diseases, and the Workplace Health Center Questionnaire of the Ministry of Health and Medical Education, and validation guidelines. Validity of questionnaire was confirmed by the content validity method and expert opinion in the specialized panel (nine expert), before we began collecting data. According to the Lavshe method, CVR was calculated to be 0.84 that is acceptable according to expert panel members. The questionnaire had 63 items in five stages of Health 
observance, Cleaning, packaging, Monitoring, and storage. It designed to evaluate the employees, scored on a scale $0-1$. On this scale, any action was graded on scale of frequency: One= Yes and Zero= No. Questionnaire included "No observation" statement. In order to keep the score, these No observation statement were not considered and were reduced from the total number in the final evaluation by the agreement of the expert panel and the professor of statistics. To obtain the 360-degree evaluation data, we distributed questionnaires to the employee and evaluators. Completed questionnaire $(n=120)$ were collected and coded data were entered into an Excel. The total score given by each evaluator was calculated for each employee. Then, a personnel statue was reported in the form of poor performance, acceptable performance, and good performance. Data were analyzed with SPSS statistical software (SPSS, Inc, version 20) by Kruskal -wallis $H$, Mann-whitney $U$ test and Pearson correlation coefficient. Normalization of data was evaluated by kolmogorov - smirnov Z test.
RESULT

A total of 30 employee participated in this study. Fifty percent of employee $(n=15)$ was female and fifty percent $(n=15)$ was men. The mean year of employee was 43.63 years (minimum 25 years, maximum 57 years). Less than fifty percent $(n=14)$ were nurses or surgical technologist, and the others were experimental technician or assistance without academic education. Over half of employees $(n=19)$ had less than ten years of sterilization experience and about sixty percent $(n=18)$ had passed in-service training. In total, hospitals sterilizer equipment's were; ethylene oxide set $(n=3)$, plasma set $(n=1)$, Dry heat oven $(n=3)$ and autoclave set $(n=13)$. All centers were equipped with an autoclave, but there was no other equipment in some hospitals.

According to the standard, all hospitals should be assigned $1 \mathrm{~m} 2$ spaces per bed to sterilization units. In this study only two hospitals matched with standard ( $E$ and F). The space of the sterilization units compared to the number of hospital beds is shown in Figure 1 .

FIGURE1. THE SPACE OF THE STERILIZATION UNIT (M2) COMPARED TO THE NUMBER OF HOSPITAL BEDS IN DIFFERENT HOSPITALS

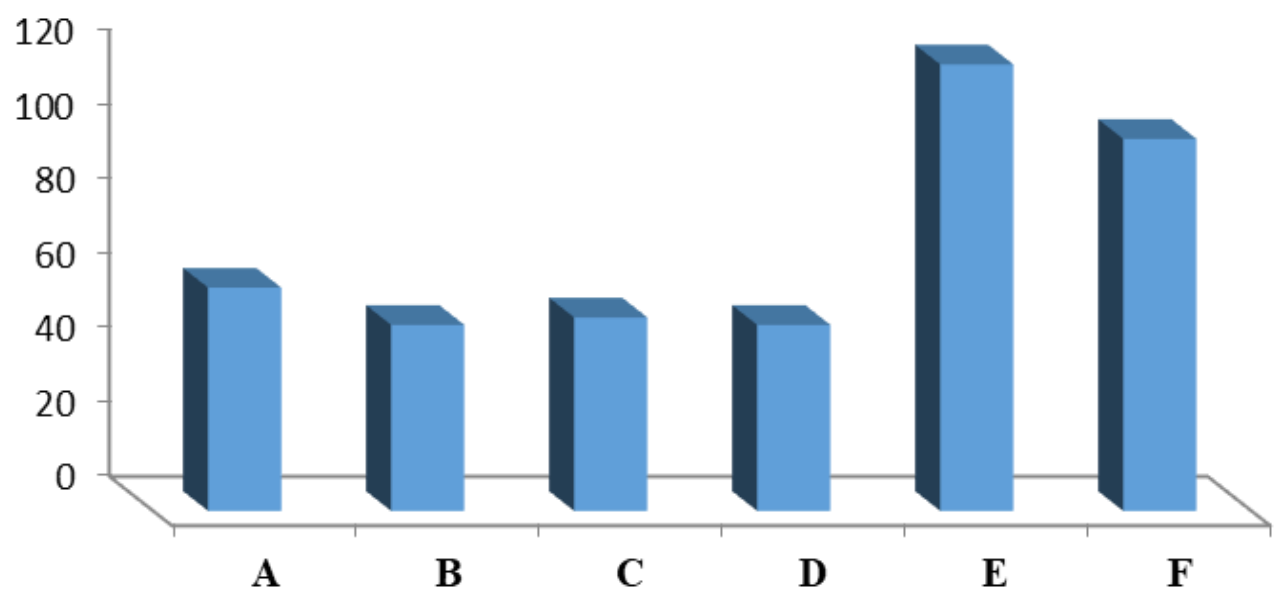

The highest mean score were as follows; infection control

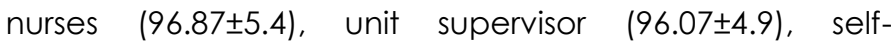
assessment (97.14 \pm 6.5$)$ in cleaning dimension and researcher $(88.21 \pm 19.6)$ in storage dimension.

The lowest mean score were as follows; infection control nurse (67.4 \pm 19.9$)$, unit supervisor (74.81 \pm 13.6$)$, researcher
(64.81 \pm 29.3$)$, and self-assessment (73.24 \pm 15.3$)$ in health dimension. Kruskal -wallis $\mathrm{H}$ Test showed a significant difference between storage and packaging dimensions and total mean scores in different groups (Table1). The highest and lowest score is given by the self-assessment and researcher, respectively. Unit supervisors and infection control nurses has been assigned the same score. 


\begin{tabular}{|c|c|c|c|c|c|c|}
\hline \multicolumn{2}{|c|}{ VIEWPOINT/DIMENSION } & \multirow{2}{*}{$\begin{array}{l}\text { RESEARCHER } \\
64.81\end{array}$} & \multirow{2}{*}{$\begin{array}{l}\text { INFECTION CONTROL } \\
\text { NURSE } \\
67.4\end{array}$} & \multirow{2}{*}{$\begin{array}{l}\text { UNIT } \\
\text { SUPERVISOR } \\
74.81\end{array}$} & \multirow{2}{*}{$\begin{array}{l}\text { SELF- } \\
\text { ASSESSMENT } \\
73.24\end{array}$} & \multirow{3}{*}{$\begin{array}{l}P \\
0.43\end{array}$} \\
\hline HEALTH & Mean & & & & & \\
\hline OBSERVANCE & SD & 29.3 & 19.9 & 13.6 & 15.3 & \\
\hline & Max & 100 & 100 & 100 & 100 & \\
\hline & Min & 11.11 & 22.22 & 55.56 & 33.33 & \\
\hline \multirow{4}{*}{ CLEANING } & Mean & 88.21 & 96.78 & 96.07 & 97.14 & \multirow{4}{*}{0.14} \\
\hline & SD & 19.6 & 5.4 & 4.9 & 6.5 & \\
\hline & Max & 100 & 100 & 100 & 100 & \\
\hline & Min & 10 & 80 & 90 & 70 & \\
\hline \multirow{4}{*}{ PACKAGING } & Mean & 71.26 & 91.94 & 90.15 & 90.88 & \multirow{4}{*}{0.002} \\
\hline & SD & 23.8 & 9.4 & 10.2 & 11.01 & \\
\hline & Max & 38.46 & 100 & 100 & 100 & \\
\hline & Min & 100 & 50 & 50 & 50 & \\
\hline \multirow{4}{*}{ MONITORING } & Mean & 81.96 & 87.69 & 88.07 & 90.62 & \multirow{4}{*}{0.089} \\
\hline & SD & 22.2 & 21.2 & 21.1 & 21.9 & \\
\hline & Max & 100 & 100 & 100 & 100 & \\
\hline & Min & 0 & 0 & 0 & 0 & \\
\hline \multirow{4}{*}{ STORAGE } & Mean & 80.83 & 95.83 & 91.66 & 90.83 & \multirow{4}{*}{0.004} \\
\hline & SD & 19.3 & 9.4 & 15.1 & 16.7 & \\
\hline & Max & 100 & 100 & 100 & 100 & \\
\hline & Min & 50 & 75 & 50 & 50 & \\
\hline \multirow{4}{*}{ TOTAL } & Mean & 75.97 & 87.62 & 87.61 & 88.01 & \multirow{4}{*}{0.029} \\
\hline & $S D$ & 18.9 & 7.2 & 7.8 & 8.1 & \\
\hline & Max & 100 & 100 & 100 & 100 & \\
\hline & Min & 22.56 & 69.57 & 66.03 & 71.79 & \\
\hline
\end{tabular}

Mann-Whitney test (Two-group analysis) showed no significant difference in total scores and different dimensions score from the point of view of the selfassessment, the unit supervisors and the infection control nurses ( $P>0.05)$. But there was a significant difference in a total score $(P=0.013)$, storage dimension $(P=0.025)$, cycle control dimension $(\mathrm{P}=0.017)$, packaging dimension $(P=0.002)$, and cleaning dimension ( $P=0.043)$ between selfassessment and researcher as an external assessment. The total score were as follows: the researcher (75.97 \pm 18.9$)$, infection control nurse (87.62 \pm 7.2$)$, unit supervisor (87.61 \pm 7.8) and self-assessment (88.01 \pm 8.1$)$.

The total mean score obtained from evaluators was $84.80 \pm 10.54$, that it was appropriate and acceptable level. The result of this study showed that male score is higher than female from a researcher's view. However, female have a higher score by the view of infection control nurse, unit staff, and unit supervisor. Mann-whitney $U$ test did not show any significant difference between male and female from four viewpoints. 
TABLE 2. STAFF PERFORMANCE ASSESSMENT SCORE IN CSSD UNIT IN DIFFERENT SEX (MEAN \pm SD)

\begin{tabular}{|l|l|l|l|l|}
\hline SEX/DIMENSION & RESEARCHER & INFECTION CONTROL NURSE & UNIT SUPERVISOR & SELF-ASSESSMENT \\
\hline MALE & $74.55 \pm 18.07$ & $88.78 \pm 5.9$ & $87.85 \pm 6.8$ & $88.77 \pm 7.2$ \\
\hline FEMALE & $77.4 \pm 20.03$ & $86.46 \pm 8.3$ & $87.37 \pm 9.02$ & $87.25 \pm 9.11$ \\
\hline P & 0.66 & 0.72 & 0.95 & 0.8 \\
\hline
\end{tabular}

The Pearson correlation coefficient showed a negative relationship between age and evaluation score from the view of a unit supervisor $(P=0.045)$, infection control nurse $(P=0.001)$, and researcher $(P=0.024)$. That is, older people had lower scores. But this relationship was not observed from the Self-assessment view $(P=0.065)$. Spearman correlation coefficient showed no significant difference between work experience in sterilization unit and evaluation score obtained from different perspectives $(P>0.05)$.

\section{DISCUSSION}

According to the findings, the highest and lowest mean score were in the Cleaning and Health observance dimensions, respectively. The self-assessment recorded higher scores for cleaning dimension, while the researcher has a different opinion as an external evaluator. In their opinion, self-assessment was given the lowest score in this dimension. All the evaluators gave the lowest score to the health observance dimension. Comparing the total scores in the evaluation, the highest score was obtained by the self-assessment, and the lowest score was obtained by the researcher. The scores of other internal evaluators (unit supervisors and infection control nurses) were the same as each other. self-assessment high scores than external evaluators are routine in the most evaluation, and this may be due to a variety of reasons, including poor knowledge and lack of appropriate training of evaluators, and concern for managers,' judgments about poor performance. Similarly to the present study, Yamani et al. evaluated the performance of emergency medicine by using a 360-degree evaluation method, the results showed that the highest score was given by the interns in selfassessment. [16]

Also, according to the results of the present study, the total score mean of different evaluators was $84.80 \pm 10.54$ which is acceptable based agreement of panel experts. Majidi et al. [17] found similar results in their study, they stated that observing the principles of infection control were acceptable by operating room staff, and sterilization process and their entry and exit controls. However, they only evaluated the process by one evaluator and observational method. No correlation was found between evaluation score and the work experience of the staff in the sterilization unit by the evaluators, which is consistent with the results of the Teymuri and Rostami studies. [18, 19] The findings of this study revealed no statistically significant difference between male and female evaluation scores regarding to different evaluators. The results of this study are different from the study of Yazdankhah. [20] They showed that male give more scores than female in the surgical department. Of course, the number of male was lower than female in the Yazdankhah study, whereas, the numbers of male and female are equal in the present study. This study reported the staffs' age was negatively correlated with performance evaluation scores (from the view of a unit supervisor, infection control nurse and researcher). It means older people has a poor performance, although the staffs don't believe it. The relationship between decreases of performance qualities and age increasing, and has been expressed in the study of Monika et al. [21] Malgorzata also emphasized that the quality of employee performance decreases in the passing of time and the managers need to consider this to maintain and enhance the efficiency of their organization. [22] According to this study, judgments and assessment of evaluators were the same in most dimensions. It is valuable in evaluating employee performance, especially in the units that it is restricted and there is a possibility of error by one person. As Chandler [23] stated in his study, a 360-degree assessment contains several points of view and can provide useful information for single assessment and needs to be repeated annually. According to the study of Kanaslan, [24] a 360-degree method have a more positive result than another traditional method. In addition, a 360-degree method is a useful method for development and also an effective tool 
for performance evaluation. Although the practical implementation of the 360-degree method is not easy, if it is used correctly, its positive results are very satisfaying. [11] Therefore, the use of the 360-degree evaluation that introduced as a tool for evaluating performance in recent years, is a comprehensive solution to the problems of single decision and judgments.

\section{CONCLUSION}

The evaluating and deciding on staff performance is an ethical issue. Therefore, it is recommended to use alternative methods such as 360-degree evaluation to prevent individual judgments or decisions based on selfassessment. The results suggest that 360-degree evaluations that incorporate multiple perspectives on staff performance might provide additional useful information. In this way, choosing the right evaluators, and training them will undoubtedly lead to valuable results. The information obtained from 360-degree evaluations can guide feedback to staffs and may lead to improved staff performance.

\section{ETHICAL CONSIDERATIONS}

Ethical issues (Including plagiarism, informed consent, misconduct, data fabrication and/or fal-sification, double publication and/or submission, redundancy, etc.) have been completely observed by the authors.

\section{LIMITATION OF RESEARCH}

In situation that there was not physical structure or standard equipment in CSSD units, assessors were unable to evaluate staff performance. So they removed the related items from the questionnaires in these situations.

\section{ACKNOWLEDGEMENTS}

This article is part of a Master thesis with the permission of IR.IUMS.REC.1397-1024 Ethics from Iran University of Medical Sciences. The researchers are grateful for the spiritual and scientific support of the Iran University of Medical Sciences. Also, the authors would like to thank all the Evaluators, and staff of the teaching hospitals of Gillan province for their cooperation, that without whom we could not complete this project.

\section{CONFLICT OF INTERESTS}

The authors declare that there is no conflict of interest.

\section{Reference:}

1. Jalalvand F, Teymouri B, Sohrabi N, Fakhri M, Shahsavari s, Jafari s. Microbial contamination of operating rooms equipment in selected hospitals in kermanshah. iranian journal of infectious disease and tropical medicine 2013;17(59):49-52.

2. Sangthong K, Soparat P, Moongtui W, Danchaivijitr S. Development of quality indicators for sterilization practices of the central sterile supply department. Journal of the Medical Association of Thailand = Chotmaihet thangphaet. 2005;10:128-32.

3. Forrester JA, Powell BL, Forrester JD, Fast C, Weiser TG. Surgical instrument reprocessing in resourceconstrained countries: A scoping review of existing methods, policies, and barriers. Surgical infections. 2018;19(6):593-602.

4. Khamir chi R, Rezaei z, Yaghobifar MA, Rakhshani M. Quality control of sterlization in the hospitals of sabzevar in 2014 sabzevar university medical science (asrar). 2017;24(4):233-237.

5. Lawrence SA, Mclntyre CA, Pulvirenti A, Seier K, Chou $Y$, Gonen M ea. Perioperative Bundle to Reduce Surgical Site Infection after Pancreaticoduodenectomy: A Prospective Cohort Study. Journal of the American College of Surgeons. 2019;228(4):595-601.

6. Basu D, Bag SC, Das A, Razario JD. The importance of paper records and their preservation period in a Central Sterile Supply Department: An experience from a oncology center in eastern India. J Infect Public Health. 2017;10(5):685-7.

7. Spry C. Understanding current steam sterilization recommendations and guidelines. Aorn J. 2008;88(4):537-50.

8. Weber DJ, Rutala WA. Assessing the risk of disease transmission to patients when there is a failure to follow recommended disinfection and sterilization guidelines. Am J Infect Control. 2013;41 (5 Suppl):031.

9. YOUSEFINEZHADI T, MOSADEGHRAD AM, ARAB M, RAMEZANI M, SARI Aa. An Analysis of Hospital Accreditation Policy in Iran. Iranian Journal of public health. 2017;46(10).

10. Mosadeghrad AM, Akbari-Sari A, Yousefinezhadi T. Evaluation of hospital accreditation in Tehran: brief report. Tehran University Medical Journal.

2018;76(5):354-9. 
11. Baradaran HR, Kheirkhah M, Keikhosravi F. Using a 360 Degree Feedback System for Performance Appraisal of Midwifery Students in Shahid Akbar Abadi Maternity Hospital. Journal of Development Strategies in Medical Education. 2016;3(1):73-80.

12. Sarraf N, Askkarkhah A, Sadati L, Hanani S. Investigating the Relationship between Compliance with Standards of Packaging of Surgical Instruments Packages and Demographic Characteristics and Length of Training of Personnel in Sterilization Centers of Guilan Educational and Medical Hospitals. 20th Annual Research Congress of Medical Students of Iran, Kermanshah. 2019;

https://www.civilica.com/Paper-AMSMED20AMSMED20_143.html.

13. Joshi R, Ling F, Jaeger J. Assessment of a 360-Degree Instrument to Evaluate Residents' Competency in Interpersonal and Communication Skills Academic Medicine. MAY 2004; 79(5):458-63.

14. Hadi Nejad F, Ahmad M, Ghasemi M. Designing a Student Performance Evaluation Model with 360 Degree Feedback Approach (Case Study: Student Performance Evaluation of Imam Ali Officer University). 2017; 16(63):1-33.

15. Ece Kuzulu Kanaslan Cemal lyem Is 360 Degree Feedback Appraisal an Effective Way of Performance Evaluation? International Journal of Academic Research in Business and Social Sciences. 2016;6(5): ISSN: 2222-6990. DOI: 10.007/IJARBSS/v6-i5/2124.

16. Yamani N, Moosavi SA, Alizadeh M, Khorvash F, Ghiasi M. A 360-degree performance evaluation of emergency medicine ward in Alzahra Hospital. J Pak Med Assoc. 2012;62(3 Suppl 2):S13-7.

17. S.A. M, Mehrabein F, R. T. Accomplish principles of infetion control by operation room s staff in the rasht hospitals Journal og gilan university of medical science. 2008;16(64):89-96.

18. Teymouri B, P. G, A. Vr, V. D, H. R, J. R. Surgery team members performance with regard to observingg infection control principle education center operation rooms of kums. Journal of kermanshah university of medical science (Behbood). 2004;8(1):51-61.

19. Rostaminejad A, Mobaraki A, Zahmatkeshan N. Performance of the Operating Room Personnel in following of the standards of Infection Control in the Educational Hospitals of Yasuj University of Medical Sciences in 2009. Armaghane danesh. 2011 ; 16(1):90-9.
20. Yazdankhah A, Tayefeh Norooz M, Ahmadi H, Aminian A, Khorgami Z, Khashayar $P$, et al. Using 360-degree multi-source feedback to evaluate professionalism in surgery departments: An Iranian perspective. Med J Islam Repub Iran 2015;29(284):1-7.

21. Monika E. von Bonsdorff, Le Zhou MW, Sinikka Vanhala, Mikaela B. von Bonsdorff. Taina RantanenEmployee Age and Company Performance: An Integrated Model of Aging and Human Resource Management Practices. Journal of Management. 2018;44(8).

22. Malgorzata Rembiasz. Impact of employee age on the safe performance of production tasks. . MATEC Web of Conferences 94 0700, DOI: 101051/matecconf/20179407009CoSME'16. 2017.

23. Chandler N, Henderson G, Park B, Byerley J, Brown WD, Steiner M J Use of a 360-Degree Evaluation in the Outpatient Setting: The Usefulness of Nurse, Faculty, Patient/Family, and Resident Self-Evaluation. Journal of Graduate Medical Education. 2010;2(3):430-4. DOI: 10.4300/JGME-D-10-00013.1.

24. Kanaslan Ece Kuzulu, Iyem Cemal. Is 360 Degree Feedback Appraisal an Effective Way of Performance Evaluation? International Journal of Academic Research in Business and Social Sciences. 2016;6(5):172- 82: DOI: 10.6007/IJARBSS/v6-i5/2124 URL: http://dx.doi.org/10.6007/IJARBSS/v6-i5/2124. 